Article

\title{
Enzymatic Degradation of Poly(ethylene 2,5-furanoate) Powders and Amorphous Films
}

\author{
Simone Weinberger ${ }^{1}$, Judit Canadell ${ }^{2}$, Felice Quartinello ${ }^{1}$, Bahar Yeniad ${ }^{2}$, Andrea Arias ${ }^{2}$, \\ Alessandro Pellis ${ }^{1, *}$ (i) and Georg M. Guebitz ${ }^{1,3}$ \\ 1 Department for Agrobiotechnology IFA-Tulln, Institute for Environmental Biotechnology, University of \\ Natural Resources and Life Sciences Vienna, Konrad Lorenz Strasse 20, 3430 Tulln an der Donau, Austria; \\ simone.weinberger@boku.ac.at (S.W.); felice.quartinello@boku.ac.at (F.Q.); guebitz@boku.ac.at (G.M.G.) \\ 2 Corbion, Central R\&D, Arkelsedijk 46, 4206 AC Gorinchem, The Netherlands; \\ judit.canadell@corbion.com (J.C.); bahar.yeniad@corbion.com (B.Y.); andrea.arias@corbion.com (A.A.) \\ 3 Austrian Centre of Industrial Biotechnology, Division Enzymes \& Polymers, Konrad Lorenz Strasse 20, \\ 3430 Tulln an der Donau, Austria \\ * Correspondence: alessandro.pellis@boku.ac.at; Tel.: +43-1-47654-97447
}

Received: 3 October 2017; Accepted: 26 October 2017; Published: 27 October 2017

\begin{abstract}
Poly(ethylene 2,5-furanoate) (PEF) is arousing great interest as a biobased alternative to plastics like poly(ethylene terephthalate) (PET) due to its wide range of potential applications, such as food and beverage packaging, clothing, and in the car industry. In the present study, the hydrolysis of PEF powders of different molecular masses $\left(M_{\mathrm{n}}=55, M_{\mathrm{w}}=104 \mathrm{~kg} / \mathrm{mol}\right.$ and $\left.M_{\mathrm{n}}=18, M_{\mathrm{w}}=29 \mathrm{~kg} / \mathrm{mol}\right)$ and various particle sizes $(180<\mathrm{d}$ and $180<\mathrm{d}<425 \mu \mathrm{m})$ using cutinase 1 from Thermobifida cellulosilytica (Thc_cut1) was studied. Thereby, the effects of molecular mass, particle size and crystallinity on enzymatic hydrolysis were investigated. The results show that particles with lower molecular mass are hydrolyzed faster than those with higher masses, and that the higher the molecular mass, the lower the influence of the particle size on the hydrolysis. Furthermore, cutinases from Humicola insolens (HiC) and Thc_cut1 were compared with regard to their hydrolytic activity on amorphous PEF films (measured as release of 2,5-furandicarboxylic acid (FDCA) and weight loss) in different reaction media $\left(1 \mathrm{M} \mathrm{KPO} \mathrm{pH} 8,0.1 \mathrm{M}\right.$ Tris- $\mathrm{HCl} \mathrm{pH} \mathrm{7)}$ and at different temperatures $\left(50^{\circ} \mathrm{C}\right.$ and $65{ }^{\circ} \mathrm{C}$ ). A $100 \%$ hydrolysis of the PEF films was achieved after only $72 \mathrm{~h}$ of incubation with a $\mathrm{HiC}$ in $1 \mathrm{M} \mathrm{KPO} \mathrm{pH} 8$ at $65^{\circ} \mathrm{C}$. Moreover, the hydrolysis reaction was monitored by LC/TOF-MS analysis of the released reaction products and by Scanning Electron Microscopy (SEM) examination of the polymer surfaces. Enzymatic hydrolysis of PEF with Thc_cut1 and HiC has potential for use in surface functionalization and recycling purposes.
\end{abstract}

Keywords: poly(ethylene 2,5-furanoate) (PEF); cutinases; enzymatic hydrolysis; polyesters; thin films; plastic recycling

\section{Introduction}

In 2015, Europe had a plastics demand of 49 million tons. Since plastics are inexpensive, durable and mechanically stable materials, they have a wide area of applications, ranging from clothing and food packaging to the construction, technical and automotive industries. However, some properties, like chemical resistance, which make petrol-based polymers especially attractive also cause disadvantages, like limited or no biodegradability and their consequent accumulation in ecosystems such as oceans and rivers [1], air pollution by incineration, and a negative impact on human health when entering the food chain $[2,3]$. Bioplastics, which refer to both biobased and biodegradable plastics, have gained attention as 'green' alternatives to petroleum-based plastics, while offering similar thermal and mechanical performance. According to European Bioplastics, the global 
production capacity of bioplastics will increase from around 4.2 million tons in 2016 to approximately 6.1 million tons in 2021. Poly(ethylene terephthalate) (PET) is the most significant polyester in terms of volume, accounting for 950,000 tons annually, worldwide [4]. It is the polyester of choice used for water and soft drink bottling, and its degradability by enzymes like esterases [5,6], lipases [6-8] and especially cutinases [9-13] has been reported, thus showing potential for recycling purposes. Furthermore, the enzymatic surface functionalization of PET is an environmentally friendly option for a broad range of applications. One example is the replacement of costly and potentially toxic chemicals with PET fiber treatment to generate the necessary concentration of nucleophilic groups on the polymer in the course of tire reinforcement [14]. In textile production, the enzymatic treatment of synthetic fibers improves hydrophilicity, which makes the textile more suitable to be in contact with the human skin [15]. The chemical reactivity of PET surfaces also can be improved by enzymatic hydrolysis. This enables the coupling of bioactive molecules suitable for medical applications [16]. Nevertheless, PET hydrolysis by enzymes is a relatively slow process, since the biocatalysts are specialized to attack natural polyesters like cutin and were not designed by nature for degrading manmade synthetic polyesters in the first instance.

To enhance their efficiency on synthetic polyesters, the molecular properties of enzymes can be engineered. Genetic modifications of a cutinase from Fusarium solani pisi, with the purpose of enlarging the active site, resulted in up to a five-fold activity increase for PET fibers when compared to the wild type. This is due to the fact that the large polymer fits better in the modified active catalytic structure of the altered biocatalyst. Another key factor for the hydrolytic activity of an enzyme is the surface hydrophobicity. Before the catalysis of a fiber, a pre-adsorption of the enzyme on the solid substrate is assumed. Since PET fibers are mostly hydrophobic, the enzyme's total hydrophobic surface affects the binding on the substrate and thus the hydrolytic efficiency $[17,18]$.

Furthermore, the presence of additives like detergents or plasticizers in the reaction significantly influences the enzymatic hydrolysis of polymers. Triton X-100 enhances conformational changes like the lid-opening of lipase from Thermomyces lanuginosa, resulting in a seven-fold increase in overall degradation products. Plasticizers reduce inter chain interactions of PET, resulting in enhanced chain mobility and, therefore, in better exposure of the outer layers of the polymer to the enzyme [19].

Despite the fact that attempts have been made to produce PET from ethylene glycol (EG) deriving from renewable resources, the terephthalic acid (TA) component is 100\% petrol-based since biobased TA is still in the research stage [20]. A potential 'green' substitute for TA is 2,5-furandicarboxylic acid (FDCA), which is a biobased building block that can be polymerized with (biobased) monoethyleneglycol (MEG) to form a 100\% biobased polyester, poly(ethylene 2,5-furanoate) (PEF).

In comparison to PET, PEF offers superior barrier properties and attractive thermal properties, i.e., processability at lower temperatures due to a lower melting temperature $\left(\mathrm{T}_{\mathrm{m}}\right)$, and the ability to withstand high temperatures due to a higher glass transition temperature $\left(\mathrm{T}_{\mathrm{g}}\right)[21,22]$. Burgess and coworkers investigated PET and amorphous PEF films (molecular weight of $182 \mathrm{~g} / \mathrm{mol}$ ) with regard to their gas permeability by complementary pressure-decay sorption and permeation techniques. The transport properties of carbon dioxide in PET and PEF were compared and quantified in terms of the Barrier Improvement Factor, calculated by the permeability of carbon dioxide in PET divided by the respective carbon dioxide permeability in PEF. Significant reduction of carbon dioxide permeability has been reported of up to 19 -fold at $35^{\circ} \mathrm{C}$ and $1 \mathrm{~atm}$ [23], as well as a drastic decrease of oxygen permeability [24]. These properties make PEF an attractive alternative to PET, especially for use as bottles and films in food packaging.

In addition to the numerous reports on PEF synthesis and characterization [25-27], to date there has only been one report on the enzymatic hydrolysis of the polymer. PEF powders with various molecular weights $(6,10$ and $40 \mathrm{kDa})$ were hydrolyzed using Thermobifida cellulosilytica cutinase 1 as catalyst with the FDCA and oligomer release profile, and were investigated via Liquid chromatography / electrospray/time-of-flight mass spectrometry (LC-MS/TOF) analysis. The enzyme was active on all tested substrates, but the crystallinity of the polymers was not taken into account [28]. 
In the present work, the hydrolysis of PEF powders of various particle sizes, various molecular masses and defined crystallinity was studied using cutinase from Thermobifida cellulosilytica and Humicola insolens. Enzymatic degradation of PEF films under different conditions, varying temperature, media and $\mathrm{pH}$, was investigated in order to identify the conditions for a $100 \%$ enzymatic degradation of PEF for recycling purposes.

\section{Results and Discussion}

\subsection{Enzymatic Hydrolysis of PEF Powders}

The hydrolysis of poly(ethylene 2,5-furanoate) (PEF) powders of different particle sizes, crystallinities and molecular masses was carried out using cutinase 1 from Thermobifida cellulosilytica (Thc_cut1) as biocatalyst. This enzyme was selected from among the variety of hydrolases available in our laboratory since it had previously been reported to hydrolyze both aliphatic poly(lactic acid) and poly(butylene succinate) (PLA, PBS) [13,29] and aromatic (PET, PEF) polyesters [30,31]. Figure 1 shows the time course hydrolysis reaction of the four different powders. Already after $24 \mathrm{~h}$ of reaction, faster hydrolysis of the amorphous powders with lower molecular masses $(C$ and $D$, Figure 1 , reaction F) was seen when compared to the samples with a $M_{\mathrm{n}}$ of 55 and a $M_{\mathrm{W}}$ of $104 \mathrm{kDa}$ and a crystallinity of $46 \%$ (A and B, Figure 1, reaction E).

After $96 \mathrm{~h}$ of reaction, the amount of released FDCA for powder A $(1.6 \mathrm{mM})$ was almost double that for powder B $(0.9 \mathrm{mM})$, despite both powders having $46 \%$ crystallinity. This is a clear proof that powders having a lower particle size are hydrolyzed faster due to the fact that more surface area is accessible to the enzyme. Regarding powders $\mathrm{C}$ and $\mathrm{D}$, a similar hydrolysis profile was observed after $96 \mathrm{~h}$, with around $2.5 \mathrm{mM}$ of released FDCA, therefore indicating that powder size has a minor impact in the hydrolytic degradation when the polymer has lower molecular masses $\left(M_{\mathrm{n}}=18, M_{\mathrm{w}}=29 \mathrm{kDa}\right)$ and crystallinity. We can conclude that particle size seems to have a minor impact when using low-molecular-weight amorphous PEF powders, and that the higher degree of hydrolysis of sample $\mathrm{C}$ and $\mathrm{D}$ is related to the low molecular weight and non-crystallinity of the samples. As previously reported for experimental PEF samples produced in our laboratory, based on their specific mechanism, biocatalysts can act in an exo- or endo-acting manner, thereby releasing, in the case of PEF, FDCA, together with several other oligomeric substances [28]. Also, in this case, a release profile consisting of FDCA and various soluble oligomers was observed (see details in Section 2.2).
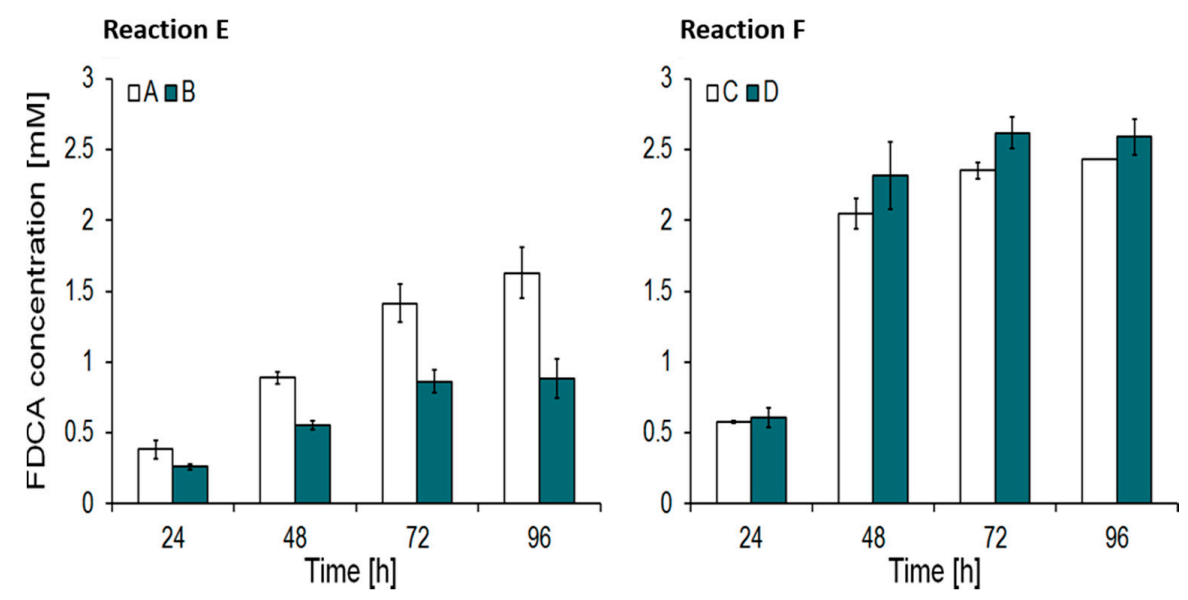

Figure 1. Enzymatic hydrolysis of poly(ethylene 2,5-furanoate) (PEF) powders (see Table 1 for powders characterization details) with different molecular weights (104 kDa (E)/29 kDA (F)), particle sizes $(\mathrm{d}<180 \mu \mathrm{m}(\mathrm{A}, \mathrm{C}) / 180<\mathrm{d}<425 \mu \mathrm{m}(\mathrm{B}, \mathrm{D}))$ and crystallinities $(46 \%$ (E)/amorphous $(\mathrm{F}))$. No release products were detected in control reactions. All experiments were performed in triplicates. 


\subsection{Enzymatic Hydrolysis of PEF Films}

After the successful hydrolysis of the various PEF powders, the enzymatic degradation of amorphous PEF films was investigated using two different enzymes; namely, cutinase 1 from Thermobifida cellulosilytica (Thc_cut1) and cutinase from Humicola insolens (HiC). The reaction was studied using two different buffers $(0.1 \mathrm{M}$ Tris- $\mathrm{HCl} \mathrm{pH} 7$ and $1 \mathrm{M} \mathrm{KPO} \mathrm{pH} 8)$ and two different reaction temperatures $\left(50^{\circ} \mathrm{C}\right.$ and $\left.65^{\circ} \mathrm{C}\right)$. The buffer and temperature selection derived from recent publications describing the efficient hydrolysis of PBS and PET using similar fungal-derived cutinases [13,31,32].

As expected, a higher enzymatic activity was observed at the highest reaction temperature, i.e., $65^{\circ} \mathrm{C}$. This is due to the fact that reaction temperatures close to the polymers' $\mathrm{T}_{\mathrm{g}}$ increase the mobility of the polymer chains, thereby facilitating the enzymatic attack, as also previously reported for PET [31]. As shown in Figure 2, after $24 \mathrm{~h}$ of incubation at $65^{\circ} \mathrm{C}, 3.1,1.9,1.6$ and 3.4 mM FDCA was released from reactions $\mathrm{G}$ (Thc_cut1, Tris-HCl), H (HiC, Tris-HCl), I (Thc_cut1, KPO) and J (Thc_cut1, KPO), respectively. An almost linear increase in the amount of FDCA was observed until $96 \mathrm{~h}$ of hydrolysis for each reaction, except for $\mathrm{G}$ and $\mathrm{H}$ at $65{ }^{\circ} \mathrm{C}$, where the reaction seemed to stagnate after only $24 \mathrm{~h}$. Based on the data, HiC showed the highest hydrolytic activity on amorphous PEF films in $1 \mathrm{M} \mathrm{KPO}$ buffer $\mathrm{pH} 8$ at $65{ }^{\circ} \mathrm{C}(12.8 \mathrm{mM}$ released FDCA after $96 \mathrm{~h})$. The unsuitability of the TRIS buffer for enzymatic hydrolysis when a total degradation of the polymer to its constituent monomers is desired has already been observed for aromatic polymers such as PET [32] and aliphatic polyesters (PBS and PHBV) [33].
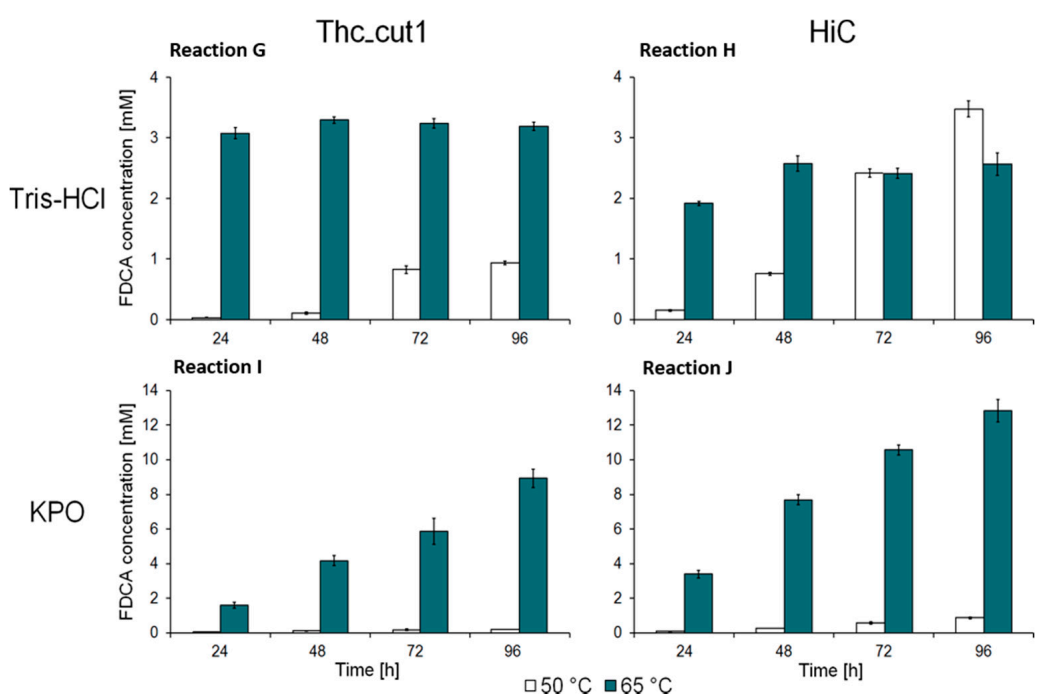

Figure 2. Enzymatic hydrolysis of amorphous PEF films. Time course reaction showing the released 2,5-furandicarboxylic acid (FDCA) for the enzymatic hydrolysis performed at 50 (white bars) and $65{ }^{\circ} \mathrm{C}$ (green bars) with Thc_cut1 (reaction G, reaction I) and $\mathrm{HiC}$ (reaction $\mathrm{H}$, reaction I) in $0.1 \mathrm{M}$ Tris- $\mathrm{HCl} \mathrm{pH}$ 7 (reaction $\mathrm{G}$, reaction $\mathrm{H}$ ) and $1 \mathrm{M} \mathrm{KPO} \mathrm{pH} 8$ (reaction $\mathrm{I}$, reaction J). No release products were detected in control reactions. All experiments were performed in triplicate.

The release of FDCA shown in Figure 2 (see also Table S1) correlates well with the weight-loss measurements shown in Figure 3 (see also Table S2). Already after only $24 \mathrm{~h}$ of incubation, the samples of reaction $\mathrm{J}$ at $65{ }^{\circ} \mathrm{C}$ show a weight loss of $43 \%$, and after $72 \mathrm{~h}$, the PEF films were completely hydrolyzed to FDCA and water-soluble oligomers. In contrast, the other reactions at this temperature show much lower weight losses in the ranges of 4-6.1 (reaction G), 7.3-8.7 (reaction $\mathrm{H}$ ) and $11.3-55.3 \%$ (reaction I). The weight losses of reactions $\mathrm{H}$ and $\mathrm{J}$ at $50{ }^{\circ} \mathrm{C}$ are clearly lower than at $65^{\circ} \mathrm{C}$; and for reactions $\mathrm{G}$ and I, no significant changes were detected when Thc_cut1 was used as catalyst (no data are shown in Figure 3 (reactions G-I) under $50{ }^{\circ} \mathrm{C}$ ). Moreover, at $50{ }^{\circ} \mathrm{C}$ the values for reaction $\mathrm{H}$ are lower than for reaction J, despite the fact that there was a higher amount of released FDCA for 
reaction $\mathrm{H}$ at this temperature (see Figure 2). This suggests a different endo-/exo type of hydrolysis preference for the biocatalysts when different reaction media and different temperatures are used. Furthermore, although the PEF films had already been 100\% degraded to soluble compounds, the amount of released FDCA was still increasing between 72 and $96 \mathrm{~h}$ in reaction $\mathrm{J}$ at $65{ }^{\circ} \mathrm{C}$ when $\mathrm{HiC}$ was used as catalyst. This suggests that the enzyme not only hydrolyzes the films, but also degrades the oligomers produced in the solution to monomers.

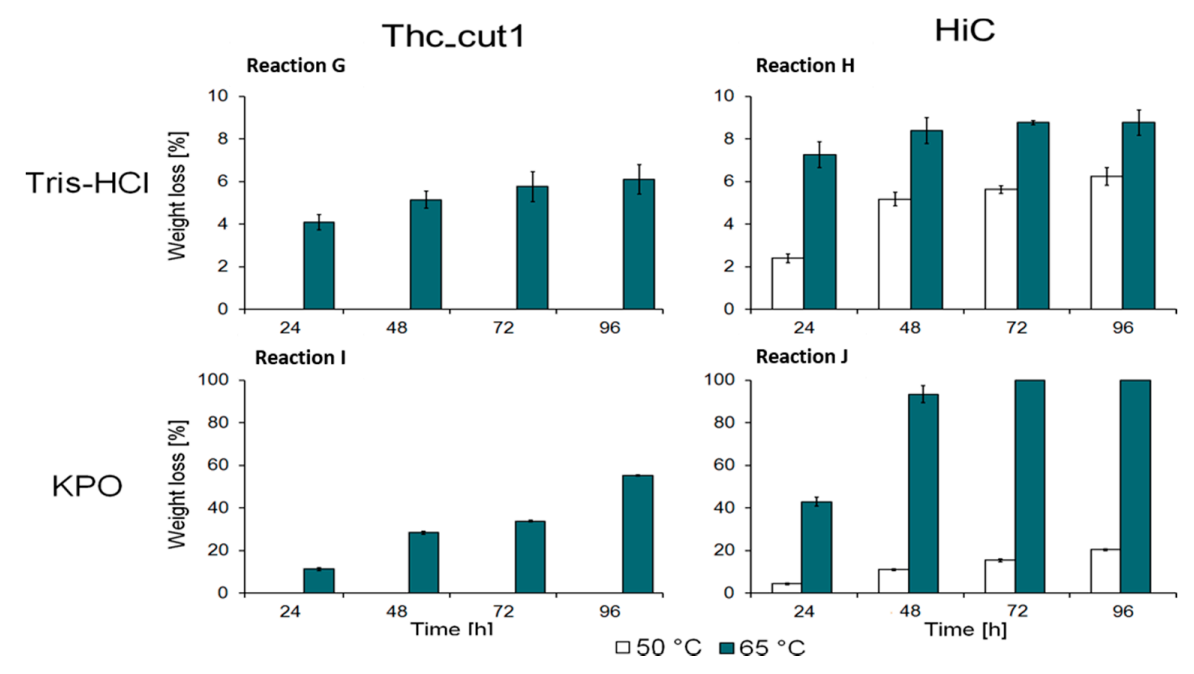

Figure 3. Enzymatic hydrolysis of amorphous PEF films. Time course reaction showing the weight loss for the enzymatic hydrolysis performed at 50 (white bars) and $65{ }^{\circ} \mathrm{C}$ (green bars) with Thc_cut1 (reaction $\mathrm{G}$, reaction $\mathrm{I}$ ) and $\mathrm{HiC}$ (reaction $\mathrm{H}$, reaction $\mathrm{J}$ ) in $0.1 \mathrm{M}$ Tris- $\mathrm{HCl} \mathrm{pH} 7$ (reaction $\mathrm{G}$, reaction $\mathrm{H}$ ) and $1 \mathrm{M} \mathrm{KPO} \mathrm{pH} 8$ (reaction I, reaction J). No detectable changes of the weight were detected in reactions $\mathrm{G}$ and I when performed with Thc_cut1 and control reactions. All experiments were performed in triplicate.

In order to confirm this release pattern, LC-MS/TOF analysis of the soluble products released by $\mathrm{HiC}$ in $1 \mathrm{M} \mathrm{KPO} \mathrm{pH} 8$ buffer at $65{ }^{\circ} \mathrm{C}$ over time was carried out. After $24 \mathrm{~h}$, several different oligomers-namely FDCA-EG, EG-FDCA-EG, FDCA-EG-FDCA, 2FDCA-2EG (see Table S3 for oligomers structure details)-were present in the sample, while only dimers and trimers were left after $48 \mathrm{~h}$. The highest number of dimers was found after $72 \mathrm{~h}$, at which point no other oligomers were detectable; and after $96 \mathrm{~h}$, not only had the PEF films been $100 \%$ degraded, but also $>95 \%$ of the oligomers had been completely hydrolyzed to monomers, as shown in Figure 4.

Our findings are perfectly aligned with the previous data collected on PET degradation, where taking particle size and crystallinity of the various PET materials into consideration had a tremendous effect on the enzymatic degradation of the polymer [31]. In addition to High Performance Liquid Chromatography (HPLC) and LC-MS/TOF analysis, scanning electron microscopy analysis of the PEF films surface was performed after $48 \mathrm{~h}$ of hydrolysis. From Figure 5 , it is possible to observe that, when compared to the blanks, PEF films show a clear degradation pattern in all tested conditions. Interestingly, $\mathrm{HiC}$ produces similar surfaces with sharp edges at $50{ }^{\circ} \mathrm{C}$ in Tris- $\mathrm{HCl}$ and at $65{ }^{\circ} \mathrm{C}$ in $\mathrm{KPO}$, while fiber-like structures were observed at $65^{\circ} \mathrm{C}$ when Tris- $\mathrm{HCl}$ was used, or smoother globular-shaped surfaces at $50^{\circ} \mathrm{C}$ when $\mathrm{KPO}$ was used. These results show the great importance of finding suitable reaction conditions when specific enzymatic surface functionalizations of the polymer are desired [20,34]. 


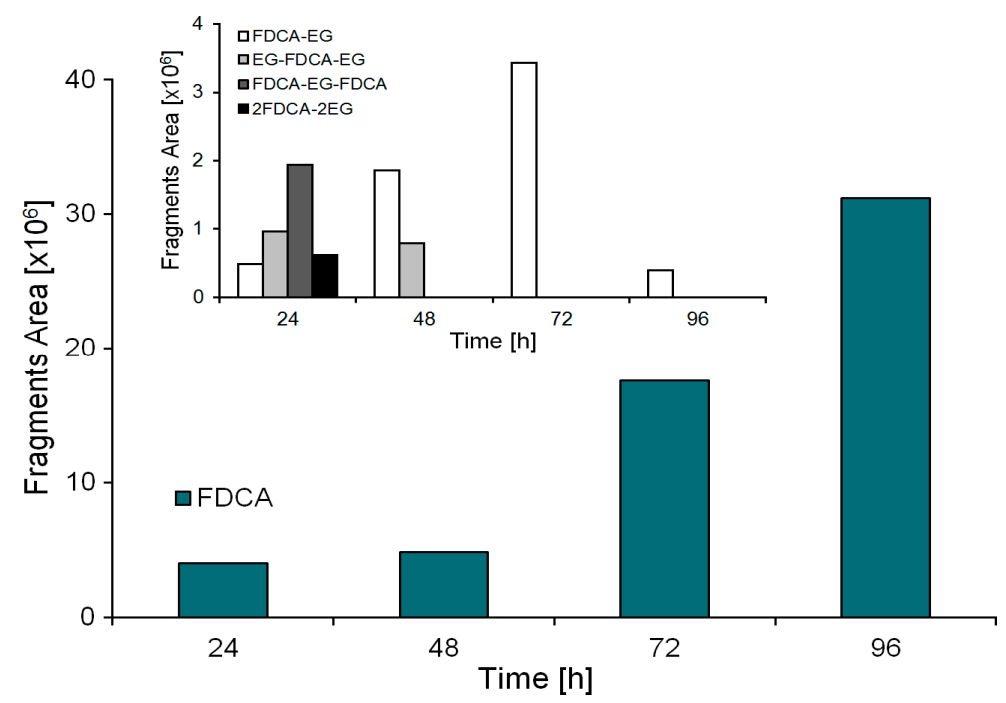

Figure 4. LC-MS/TOF analysis of the released oligomers in comparison to FDCA release in samples of $\mathrm{HiC}$ in $1 \mathrm{M} \mathrm{KPO} \mathrm{pH} 8$ at $65^{\circ} \mathrm{C}$. No release products were detected in the control reactions. Inset figure: released oligomers composed of furan dicarboxylic acid and ethylene glycol up to DP4.

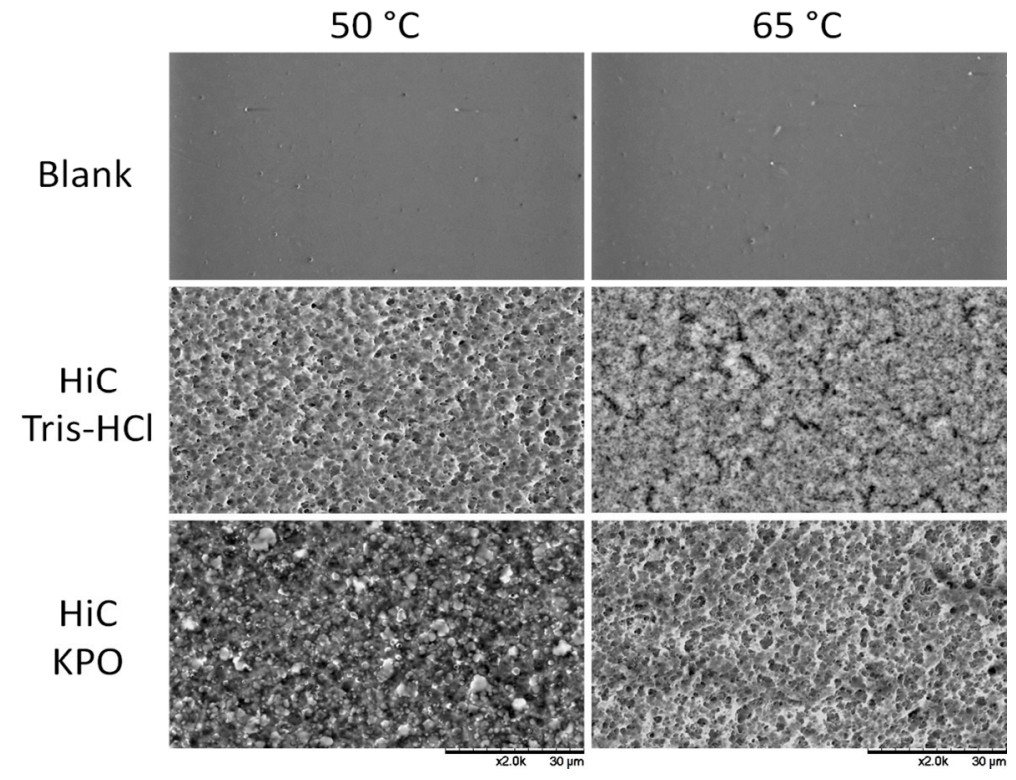

Figure 5. Scanning Electron Microscopy (SEM) pictures of amorphous PEF films after 48 h enzymatic hydrolysis with $\mathrm{HiC}$ in $0.1 \mathrm{M}$ Tris- $\mathrm{HCl} \mathrm{pH} 7$ (middle) and $1 \mathrm{M} \mathrm{KPO} \mathrm{pH} 8$ (bottom). Left side shows films with $50{ }^{\circ} \mathrm{C}$, right side shows films with $65{ }^{\circ} \mathrm{C}$ reaction temperature. The upper pictures show the control reactions.

\section{Materials and Methods}

\subsection{Chemicals, Reagents and Enzymes}

Poly(ethylene 2,5-furanoate) (PEF) powders and films were supplied by Corbion (Amsterdam, The Netherlands). Table 1 shows the molecular weight $\left(M_{\mathrm{n}}\right.$ and $\left.M_{\mathrm{w}}\right)$, the polydispersity index (PDI), the diameter and the crystallinity of the powders. The latter was evaluated as the ratio of the enthalpy of melting of the sample measured by Differential Scanning Calorimetry (DCS) (1st heating at $10^{\circ} \mathrm{C} / \mathrm{min}$ ) and the standard melting enthalpy $\Delta \mathrm{H}_{\mathrm{m}}{ }^{\circ}$ of $\mathrm{PEF}$, estimated as $140 \pm 5 \mathrm{~J} / \mathrm{g}$ according Stoclet et al. [35]. 
The PEF film samples had a molecular weight of $M_{\mathrm{n}}=25 \mathrm{~kg} / \mathrm{mol}, M_{\mathrm{w}}=43 \mathrm{~kg} / \mathrm{mol}$ and a PDI of 1.7. 2,-5-Furandicarboxylic acid (FDCA) and all other chemicals and solvents were purchased from Sigma-Aldrich at reagent grade, and used without further purification if not otherwise specified.

Table 1. Characterization of the synthesized PEF powders. PDI: polydispersity index.

\begin{tabular}{cccccc}
\hline Sample Name & $\boldsymbol{M}_{\mathbf{n}}(\mathbf{k D a}){ }^{*}$ & $\boldsymbol{M}_{\mathbf{w}} \mathbf{( k D a )}$ & PDI $^{*}$ & Diameter $(\boldsymbol{\mu m})$ & Crystallinity $(\%)$ \\
\hline A & 55 & 104 & 1.9 & $\mathrm{~d}<80$ & 46 \\
B & 55 & 104 & 1.9 & $180<\mathrm{d}<425$ & 46 \\
C & 18 & 29 & 1.8 & $\mathrm{~d}<180$ & amorphous \\
D & 18 & 29 & 1.8 & $180<\mathrm{d}<425$ & amorphous \\
\hline \multicolumn{5}{c}{ * determined via Size Exclusion Chromatography (SEC). }
\end{tabular}

Cutinase from Humicola insolens (HiC) was obtained from Novozymes and used as received without further purification. Cutinase 1 from Thermobifida cellulosilytica (Thc_cut1) was produced and purified as previously described [14].

\subsection{Esterase Activity and Protein Concentration Assays}

Enzymatic activity (PNPB assay) and protein concentration determination according to the BioRad protein assay (Bio-Rad Laboratories GmbH, Vienna, Austria, Catalyst No.: 500-0006) were carried out as previously described [36].

\subsection{Poly(ethylene 2,5-furanoate) Powders \& Films Hydrolysis}

$5.0 \mathrm{mg}$ of the PEF powders provided by Corbion were incubated with $1.0 \mathrm{~mL}$ of $5 \mu \mathrm{M}$ of Thc_cut1 in $1 \mathrm{M} \mathrm{KPO}$ buffer $\mathrm{pH}$ 8. Incubations were conducted in an orbital shaker set at $100 \mathrm{rpm}$ and 50 or $65^{\circ} \mathrm{C}$ since good biocatalyst stability and activity over time had been previously reported for these conditions $[13,30,31]$. Blank reactions were carried out in buffer without addition of the biocatalyst. All reactions were performed in triplicate.

PEF film samples of $0.5 \times 1.0 \mathrm{~cm}^{2}$ provided by Corbion were washed 3 times as previously described for PET and PLA films [29,30]. After washing, the films were incubated with $1.0 \mathrm{~mL}$ of $5 \mu \mathrm{M}$ HiC or Thc_cut1 in $0.1 \mathrm{M}$ Tris-HCl buffer $\mathrm{pH} 7$ or $1 \mathrm{M} \mathrm{KPO}$ buffer $\mathrm{pH} 8$ for $24,48,72$ or $96 \mathrm{~h}$. Incubations were performed with the same settings as the powders. For the films, the \% weight loss in the course of the enzymatic reaction was calculated after the washing and drying of the samples (Table 2).

Table 2. Overview PEF film hydrolysis samples.

\begin{tabular}{ccc}
\hline Sample Name & Enzyme & Buffer \\
\hline G & Thc_Cut1 & Tris-HCl (0.1 M, pH 7) \\
H & HiC & KPO (1 M, pH 8) \\
\hline I & Thc_Cut1 & \\
J & HiC & \\
\hline
\end{tabular}

\subsection{High-Performance Liquid Chromatography (HPLC-DAD)}

After enzymatic treatment of polyester powders/films the biocatalyst was precipitated with ice cold MeOH. Samples were centrifuged (Hettich MIKRO 200 R, Tuttlingen, Germany) at 14,000 rpm at $0{ }^{\circ} \mathrm{C}$ for $15 \mathrm{~min}$. The resulting supernatant was filtered $(0.45 \mu \mathrm{m}$ PTFE filters) and filled in a HPLC vial. For HPLC (Agilent Technologies, 1260 Infinity, Palo Alto, CA, USA) analysis, a reversed phase column C18 (YMC 30, $250 \times 4.6 \mathrm{~mm}$ ID, S-5 $\mu \mathrm{m}$ ) was used. Analysis was carried out using a $\mathrm{H}_{2} \mathrm{O} / \mathrm{MeOH} / \mathrm{HCOOH}$ gradient. The flow rate was set to $0.85 \mathrm{~mL} \mathrm{~min}^{-1}$ and the column was maintained at a temperature of $40^{\circ} \mathrm{C}$. The injection volume was $10 \mu \mathrm{L}$. Detection of the analytes was performed with a photodiode array detector (Agilent Technologies, 1290 Infinity II, Vienna, Austria) at 
a wavelength of $260 \mathrm{~nm}$. A FDCA standard calibration curve treated the same way as samples was also prepared and used for quantification (see Figure S1).

\subsection{Scanning Electron Microscopy (SEM)}

The surface morphology of enzymatically hydrolyzed films was observed after $48 \mathrm{~h}$ using SEM. A control sample consisting of a PEF film without enzymatic treatment was also measured.

All SEM images were acquired by collecting secondary electrons on a Hitachi 3030TM (Metrohm INULA GmbH, Vienna, Austria) working at Energy Dispersive Xray Spectrom (EDX) acceleration voltage.

\subsection{LC-MS/TOF Analysis}

Samples used for the HPLC analysis were diluted in MeOH and filtered through $0.20 \mu \mathrm{m}$ PTFE filters. Liquid chromatography/electrospray/time-of-flight mass spectrometry (LC-MS/TOF) in positive ionization mode was used to separate and identify the release products. The analytes were separated using an HPLC (1260 series, Agilent Technologies, Palo Alto, CA, USA) equipped with a reversed-phase C18 rapid resolution column (Waters Xterra, Milford, MA, USA) of $3.0 \times 15 \mathrm{~mm}$ and $3.5 \mu \mathrm{m}$ particle diameter. Mobile phase A was $\mathrm{mQ} \mathrm{H}_{2} \mathrm{O}$ with $0.1 \%$ formic acid, and mobile phase $\mathrm{B}$ consisted of $\mathrm{MeOH}$. Analyses were carried out using a gradient similar to that previously reported [28]. The flow rate was set to $1.0 \mathrm{~mL} \mathrm{~min}{ }^{-1}$ and the column was maintained at a temperature of $30^{\circ} \mathrm{C}$. The injection volume was $1.0 \mu \mathrm{L}$. Detection of the analytes was performed with a photodiode array detector at the wavelength of $254 \mathrm{~nm}$. The HPLC system was connected to a time-of-flight mass spectrometer (6230 TOF LC/MS, Agilent Technologies) equipped with an electrospray interface under the following operating parameters: capillary $3500 \mathrm{~V}$, nebulizer $20 \mathrm{psig}$, drying gas $10 \mathrm{~L} \mathrm{~min}^{-1}$, gas temperature $325^{\circ} \mathrm{C}$, fragmentator $200 \mathrm{~V}$, skimmer $65 \mathrm{~V}$, OCT $1 \mathrm{RF}$ Vpp $750 \mathrm{~V}$. The mass axis was calibrated using the mixture provided by the manufacturer over the $m / z 50-3000$ range. A second orthogonal sprayer with a solution was used as a continuous calibration using the following reference masses: 121.050873 and $922.009798 \mathrm{~m} / z$. Spectra were acquired over the $m / z$ 100-3000 range at a scan rate of 2 spectra s ${ }^{-1}$.

\subsection{Size Exclusion Chromatography (SEC)}

Molecular weights $\left(M_{\mathrm{n}}, M_{\mathrm{w}}\right)$ and polydispersity $\left(M_{\mathrm{w}} / M_{\mathrm{n}}\right)$ were determined by Size Exclusion Chromatography (SEC) performed on a Malvern Viscotek TDAMax VE2001 (Malvern, UK), equipped with a light scattering detector, viscosity and concentration detectors. Samples were filtered over a $0.45 \mu \mathrm{m}$ PVDF filter. The eluent was hexafluoroisopropanol (HFiP) $+0.02 \mathrm{M} \mathrm{CF}_{3} \mathrm{COOK}_{\text {at a flow }}$ rate of $0.70 \mathrm{~mL} / \mathrm{min}$ running at $40^{\circ} \mathrm{C}$ over two PSS PFG (Polymer Standard Service) analytical linear $\mathrm{M}$ columns. The absolute molecular weights were calculated using multi detector calibration and a narrow PolyCALTMStd-PMMA-65K standard (Malvern, UK).

\section{Conclusions}

PEF powders of two different particle sizes $(180<\mathrm{d}$ and $180<\mathrm{d}<425 \mu \mathrm{m})$ and two different molecular weights $\left(M_{\mathrm{n}}=55, M_{\mathrm{w}}=104 \mathrm{~kg} / \mathrm{mol}\right.$ and $\left.M_{\mathrm{n}}=18, M_{\mathrm{w}}=29 \mathrm{~kg} / \mathrm{mol}\right)$ were successfully hydrolyzed using Thc_cut1 in Tris-HCl buffer $\mathrm{pH}$ 7. The collected data show that the enzymatic hydrolysis of powders having lower molecular masses and lower crystallinity (C \& D) is faster than the hydrolysis of powders with higher molecular masses and crystallinity (A \& B). We can conclude that particle size seems to have a minor impact when using low-molecular-weight amorphous PEF powders, and that the higher degree of hydrolysis of sample $C$ and $D$ is related to the low molecular weight and non-crystallinity of the samples.

Amorphous PEF films were hydrolyzed at 50 and $65{ }^{\circ} \mathrm{C}$ with cutinase 1 from Thermobifida cellulosilytica (Thc_cut1) (reaction G, reaction I) and cutinase from Humicola insolens (HiC) (reaction $\mathrm{H}$, reaction J), each one in $0.1 \mathrm{M}$ Tris- $\mathrm{HCl} \mathrm{pH} 7$ (reaction $\mathrm{G}$, reaction $\mathrm{H}$ ) and $1 \mathrm{M} \mathrm{KPO} \mathrm{pH} 8$ (reaction I, 
reaction J). Both enzymes are active under the tested conditions, but $\mathrm{HiC}$ in $1 \mathrm{M} \mathrm{KPO} \mathrm{pH} 8$ at $65^{\circ} \mathrm{C}$ (J) clearly shows the highest hydrolytic activity on PEF films, leading to a $100 \%$ degradation of the polymer to soluble molecules after only $72 \mathrm{~h}$ of reaction. According to LC-MS/TOF analysis, HiC released both FDCA and oligomers, which were further degraded to monomers over time.

Also interesting to note is that, depending on the reaction conditions used, SEM characterization of the PEF films surface underlines the formation of different surface patterns. The fine tuning of enzymatic hydrolysis by controlling various parameters might open up possibilities for both surface functionalization and polymer recycling purposes.

Supplementary Materials: The following are available online at www.mdpi.com/2073-4344/7/11/318/s1. Figure S1: FDCA calibration used for the analysis of molecules released from PEF by the enzymes, Table S1: HPLC data of released FDCA for the enzymatic hydrolysis performed at 50 and $65{ }^{\circ} \mathrm{C}$ with Thc_cut 1 and HiC respectively in $0.1 \mathrm{M}$ Tris- $\mathrm{HCl} \mathrm{pH} 7$ and $1 \mathrm{M} \mathrm{KPO} \mathrm{pH} \mathrm{8,} \mathrm{Table} \mathrm{S2:} \mathrm{weight} \mathrm{loss} \mathrm{data} \mathrm{for} \mathrm{the} \mathrm{enzymatic} \mathrm{hydrolysis}$ performed at 50 and $65^{\circ} \mathrm{C}$ with The_cut1 and $\mathrm{HiC}$ respectively in $0.1 \mathrm{M}$ Tris- $\mathrm{HCl} \mathrm{pH} 7$ and $1 \mathrm{M} \mathrm{KPO} \mathrm{pH} 8$, Table S3: LC/TOF-MS detected release products after enzymatic hydrolysis of PEF.

Acknowledgments: This work has been supported by the Federal Ministry of Science, Research and Economy (BMWFW), the Federal Ministry of Traffic, Innovation and Technology (bmvit), the Styrian Business Promotion Agency SFG, the Standortagentur Tirol, and the Government of Lower Austria and Business Agency Vienna through the COMET-Funding Program managed by the Austrian Research Promotion Agency FFG.

Author Contributions: Alessandro Pellis and Judit Canadell conceived and designed the experiments; Simone Weinberger, Alessandro Pellis, Felice Quartinello, Bahar Yeniad and Andrea Arias performed the experiments; Simone Weinberger and Alessandro Pellis analyzed the data; Bahar Yeniad and Andrea Arias synthesized the PEF powders and produced the films; Judit Canadell and Simone Weinberger performed the SEM analysis; Simone Weinberger, Alessandro Pellis and Georg M. Guebitz wrote the paper.

Conflicts of Interest: The authors declare no conflict of interest.

\section{References}

1. Lechner, A.; Keckeis, H.; Lumesberger-Loisl, F.; Zens, B.; Krusch, R.; Tritthart, M.; Glas, M.; Schludermann, E. The danube so colourful: A potpourri of plastic litter outnumbers fish larvae in europe's second largest river. Environ. Pollut. 2014, 188, 177-181. [CrossRef] [PubMed]

2. Steiner, A. Emerging issues in our global environment. In UNEP Year Book; UNEP: Nairobi, Kenya, 2014.

3. Hopewell, J.; Dvorak, R.; Kosior, E. Plastics recycling: Challenges and opportunities. Philos. Trans. B Biol. Sci. 2009, 364, 2115-2126. [CrossRef] [PubMed]

4. E. Bioplastics. Available online: http://www.european-bioplastics.org/market/ (accessed on 22 August 2017).

5. Alisch, M.; Feuerhack, A.; Müller, H.; Mensak, B.; Andreaus, J.; Zimmermann, W. Biocatalytic modification of polyethylene terephthalate fibres by esterases from actinomycete isolates. Biocatal. Biotransf. 2004, 22, 347-351. [CrossRef]

6. Heumann, S.; Eberl, A.; Pobeheim, H.; Liebminger, S.; Fischer-Colbrie, G.; Almansa, E.; Cavaco-Paulo, A.; Gubitz, G.M. New model substrates for enzymes hydrolysing polyethyleneterephthalate and polyamide fibres. J. Biochem. Biophys. Methods 2006, 69, 89-99. [CrossRef] [PubMed]

7. Vertommen, M.; Nierstrasz, V.A.; van der Veer, M.; Warmoeskerken, M.M.C.G. Enzymatic surface modification of poly(ethylene terephthalate). J. Biotechnol. 2005, 120, 376-386. [CrossRef] [PubMed]

8. Müller, R.J.; Schrader, H.; Profe, J.; Dresler, K.; Deckwer, W.D. Enzymatic degradation of poly (ethylene terephthalate): Rapid hydrolyse using a hydrolase from T. fusca. Macromol. Rapid Commun. 2005, 26, 1400-1405. [CrossRef]

9. Ferrario, V.; Pellis, A.; Cespugli, M.; Guebitz, G.M.; Gardossi, L. Nature Inspired Solutions for Polymers: Will Cutinase Enzymes Make Polyesters and Polyamides Greener? Catalysts 2017, 6, 205. [CrossRef]

10. Pellis, A.; Cantone, S.; Ebert, C.; Gardossi, L. Evolving biocatalysis to meet bioeconomy challenges and opportunities. New Biotechnol. 2017, in press. [CrossRef] [PubMed]

11. Then, J.; Wei, R.; Oeser, T.; Barth, M.; Belisário-Ferrari, M.R.; Schmidt, J.; Zimmermann, W. $\mathrm{Ca}^{2+}$ and $\mathrm{Mg}^{2+}$ binding site engineering increases the degradation of polyethylene terephthalate films by polyester hydrolases from Thermobifida fusca. Biotechnol. J. 2015, 10, 592-598. [CrossRef] [PubMed] 
12. Alisch-Mark, M.; Herrmann, A.; Zimmermann, W. Increase of the hydrophilicity of polyethylene terephthalate fibres by hydrolases from Thermomonospora fusca and Fusarium solanif. sp. pisi. Biotechnol. Lett. 2006, 28, 681-685. [CrossRef] [PubMed]

13. Weinberger, S.; Haernvall, K.; Scaini, D.; Ghazaryan, G.; Zumstein, M.Z.; Sander, M.; Pellis, A.; Guebitz, G.M. Enzymatic surface hydrolysis of poly(ethylene furanoate) thin films of various crystallinities. Green Chem. 2017. [CrossRef]

14. Vecchiato, S.; Ahrens, J.; Pellis, A.; Scaini, D.; Mueller, B.; Herrero Acero, E.; Guebitz, G.M. Enzymatic Functionalization of HMLS-Polyethylene Terephthalate Fabrics Improves the Adhesion to Rubber. ACS Sustain. Chem. Eng. 2017, 5, 6456-6465. [CrossRef]

15. Silva, C.M.; Carneiro, F.; O’Neill, A.; Fonseca, L.P.; Cabral, J.S.; Guebitz, G.M.; Cavaco-Paulo, A. Cutinase-A new tool for biomodification of synthetic fibers. J. Polym. Sci. Part A Polym. Chem. 2005, 43, 2448-2450. [CrossRef]

16. Guebitz, G.M.; Cavaco-Paulo, A. Enzymes go big: Surface hydrolysis and functionalisation of synthetic polymers. Trends Biotechnol. 2008, 26, 32-38. [CrossRef] [PubMed]

17. Araújo, R.; Silva, C.; O’Neill, A.; Micaelo, N.; Guebitz, G.M.; Soares, C.M.; Casal, M.; Cavaco-Paulo, A. Tailoring cutinase activity towards polyethylene terephthalate and polyamide 6,6 fibers. J. Biotechnol. 2007, 128, 849-857. [CrossRef] [PubMed]

18. Herrero Acero, E.; Ribitsch, D.; Dellacher, A.; Zitzenbacher, S.; Marold, A.; Steinkellner, G.; Gruber, K.; Schwab, H.; Guebitz, G.M. Surface engineering of a cutinase from Thermobifida cellulosilytica for improved polyester hydrolysis. Biotechnol. Bioeng. 2013, 110, 2581-2590. [CrossRef] [PubMed]

19. Eberl, A.; Heumann, S.; Brückner, T.; Araujo, R.; Cavaco-Paulo, A.; Kaufmann, F.; Kroutil, W.; Guebitz, G.M. Enzymatic surface hydrolysis of poly(ethylene terephthalate) and bis(benzoyloxyethyl) terephthalate by lipase and cutinase in the presence of surface active molecules. J. Biotechnol. 2009, 143, 207-212. [CrossRef] [PubMed]

20. Pellis, A.; Herrero Acero, E.; Gardossi, L.; Ferrario, V.; Guebitz, G.M. Renewable building blocks for sustainable polyesters: New biotechnological routes for greener plastics. Polym. Int. 2016, 65, 861-871. [CrossRef]

21. Papageorgiou, D.G.; Guigo, N.; Tsanaktsis, V.; Exarhopoulos, S.; Bikiaris, D.N.; Sbirrazzuoli, N.; Papageorgiou, G.Z. Fast Crystallization and Melting Behavior of a Long-Spaced Aliphatic Furandicarboxylate Biobased Polyester, Poly (dodecylene 2, 5-furanoate). Ind. Eng. Chem. Res. 2016, 55, 5315-5326. [CrossRef]

22. Knoop, J.R.I.; Vogelzang, W.; van Haveren, J.; van Es, D.S. High molecular weight poly(ethylene-2,5-furanoate); critical aspects in synthesis and mechanical property determination. J. Polym. Sci. Part A Polym. Chem. 2013, 51, 4191-4199. [CrossRef]

23. Burgess, S.K.; Kriegel, R.M.; Koros, W.J. Carbon Dioxide Sorption and Transport in Amorphous Poly(ethylene furanoate). Macromolecules 2015, 48, 2184-2193. [CrossRef]

24. Burgess, S.K.; Karvan, O.; Johnson, J.; Kriegel, R.M.; Koros, W.J. Oxygen sorption and transport in amorphous poly (ethylene furanoate). Polymer 2014, 55, 4748-4756. [CrossRef]

25. Konstantopoulou, M.; Terzopoulou, Z.; Nerantzaki, M.; Tsagkalias, J.; Achilias, D.S.; Bikiaris, D.N.; Exarhopoulos, S.; Papageorgiou, D.G.; Papageorgiou, G.Z. Poly(ethylene furanoate-co-ethylene terephthalate) biobased copolymers: Synthesis, thermal properties and cocrystallization behavior. Eur. Polym. J. 2017, 89, 349-366. [CrossRef]

26. Pellis, A.; Guarneri, A.; Brandauer, M.; Herrero Acero, E.; Peerlings, H.; Gardossi, L.; Guebitz, G.M. Exploring mild enzymatic sustainable routes for the synthesis of bio-degradable aromatic-aliphatic oligoesters. Biotechnol. J. 2016, 11, 642-647. [CrossRef] [PubMed]

27. Jiang, Y.; Woortman, A.J.J.; van Ekenstein, G.; Loos, K. A biocatalytic approach towards sustainable furanic-aliphatic polyesters. Polym. Chem. 2015, 6, 5198-5211. [CrossRef]

28. Pellis, A.; Haernvall, K.; Pichler, C.M.; Ghazaryan, G.; Breinbauer, R.; Guebitz, G.M. Enzymatic hydrolysis of poly(ethylene furanoate). J. Biotechnol. 2016, 235, 47-53. [CrossRef] [PubMed]

29. Ribitsch, D.; Zitzenbacher, S.; Zartl, B.; Gamerith, C.; Pellis, A.; Jungbauer, A.; Łyskowski, A.; Steinkellner, G.; Gruber, K.; Tscheliessnig, R.; et al. Small cause, large effect: Structural characterization of cutinases from Thermobifida cellulosilytica. Biotechnol. Bioeng. 2017, 114, 2481-2488. [CrossRef] [PubMed] 
30. Pellis, A.; Gamerith, C.; Ghazaryan, G.; Ortner, A.; Herrero Acero, E.; Guebitz, G.M. Ultrasound-enhanced enzymatic hydrolysis of poly(ethylene terephthalate). Bioresource Technol. 2016, 218, 1298-1302. [CrossRef] [PubMed]

31. Gamerith, C.; Zartl, B.; Pellis, A.; Guillamot, F.; Marty, A.; Herrero Acero, E.; Guebitz, G.M. Enzymatic recovery of polyester building blocks from polymer blends. Process Biochem. 2017, 59, 58-64. [CrossRef]

32. Schmidt, J.; Oeser, T.; Belisário-Ferrari, M.R.; Barth, M.; Then, J.; Zimmermann, W. Effect of Tris, MOPS, and phosphate buffers on the hydrolysis of polyethylene terephthalate films by polyester hydrolases. FEBS Open Bio 2016, 6, 919-927. [CrossRef] [PubMed]

33. Gamerith, C.; Vastano, M.; Ghorbanpour, S.M.; Zitzenbacher, S.; Ribitsch, D.; Zumstein, M.T.; Sander, M.; Herrero Acero, E.; Pellis, A.; Guebitz, G.M. Enzymatic Degradation of Aromatic and Aliphatic Polyesters by P. pastoris Expressed Cutinase 1 from Thermobifida cellulosilytica. Front. Microbiol. 2017, 8, 938. [CrossRef] [PubMed]

34. Pellis, A.; Ferrario, V.; Ribitsch, D.; Guebitz, G.M.; Gardossi, L. The closure of the cycle: Enzymatic synthesis and functionalization of bio-based polyesters. Trends Biotechnol. 2016, 34, 316-328. [CrossRef] [PubMed]

35. Stoclet, G.; Gobius du Sart, G.; Yeniad, B.; de Vos, S.; Lefebvre, J.M. Isothermal crystallization and structural characterization of poly(ethylene-2,5-furanoate). Polymer 2015, 72, 165-176. [CrossRef]

36. Pellis, A.; Herrero Acero, E.; Weber, H.; Obersriebnig, M.; Srebotnik, E.; Guebitz, G.M. Biocatalyzed approach for the surface functionalization of poly(L-lactic acid) films using hydrolytic enzyme. Biotechnol. J. 2015, 10, 1739-1749. [CrossRef] [PubMed]

(C) 2017 by the authors. Licensee MDPI, Basel, Switzerland. This article is an open access article distributed under the terms and conditions of the Creative Commons Attribution (CC BY) license (http:/ / creativecommons.org/licenses/by/4.0/). 